\title{
TRIBUTE TO DR. DARCY DILLENBURG
}

I was asked to open this session, which is a tribute of the plasma physics community to Dr. Darcy Dillenburg. Many of us, present in this session, have known Prof. Dillenburg for long time, we have worked with him, and we know very well why this tribute session has been organized in honor of him. However, we have here some visitors who are not well acquainted with Prof. Dillenburg, we have also younger people who are not familiar with him, and therefore it is opportune to dwell a little bit upon the story of Prof. Dillenburg's life, and specially about his significance to the plasma physics community in Brazil.

Prof. Dillenburg graduated in Physics in 1953, in the University which is now the Federal University of Rio Grande do Sul (UFRGS), in Porto Alegre, capital of the southernmost State in Brazil. He was the fourth person to graduate in Physics there, where the Physics course had been created in 1945. Accordingly to what we learned from a colleague at his high school period, at that time before University he already distinguished himself among his peers as a very bright young fellow, interested in physical sciences.

In the same year in which Prof. Dillenburg was graduating as a Bachelor in Physics, the University was creating the Center for Physical Research, and the Faculty of Philosophy was creating the Department of Mathematics and Physics. It was a period where the importance of physical sciences was increasingly being recognized by the whole society. Around this period of time started to operate in the big cities of Rio de Janeiro and São Paulo institutions like the Brazilian Center for Physical Research (CBPF), the Institute of Pure and Applied Mathematics (IMPA), and the Institute for Atomic Energy. It was at the latter, connected to the University of São Paulo, that the young Darcy Dillenburg started his career as a researcher, staying there nearly two years, from 1956 to 1958.

After this period in São Paulo, Prof. Dillenburg returned to Porto Alegre, where along with other enthusiastic young men worked to create and organize the Institute of Physics. The Institute was created in 1959, and it has grown to become recognized as one of the Institutes more active in research, at the University of Rio Grande do Sul.

It is certainly not my intention to give a detailed account of Prof. Dillenburg's life. However, regarding these general professional features, I wish only to add that since the start of the Institute of Physics at UFRGS Prof. Dillenburg played there a leading role, not only helping to create the sense of the importance of significant research activity, but also fostering activities connected with Physics Education and with the interaction of the University with a larger community, for instance promoting activities of continued education for teachers of secondary schools. As an Administrator, among other activities, Prof. Dillenburg spent two years as Head of the Physics Department, and four years as Director of the Institute of Physics. He also played important roles in the Administration of the University, and was also very active in the physics and educational community at national level, and occupied a position as Director of Evaluation Programs at CAPES, the Brazilian agency connected to the Ministry of Education which deals with the network of Brazilian Universities. From the point of view of his scientific life, it may be mentioned that he spent different periods of time at the Universidade Nacional Autônoma do México, at the Carnegie Institute of Technology, U.S.A., at the Centre d'Etudes Nucléaires de Fontenay-aux-Roses, France, and at the University of Maryland, USA. He worked in different fields, like Physics of Nuclear Reactors, Hyperfine Interactions and Perturbed Angular Correlations, Field Theory and Quantum Electrodynamics, and Plasma Physics.

In all of these activities, Prof. Dillenburg has left his mark as someone very able to establish clear objectives, very effective in the task of putting people with different points of view to work together toward a common objective which was perceived to be important, and well known for his long range vision.

After this short description of Prof. Dillenburg's academic life, and after an even shorter and necessarily incomplete description of his personality, let us concentrate a little bit on the subject which is closer to us at the present meeting, Plasma Physics. Let us mention a few facts and opinions about the role of Prof. Dillenburg regarding the activities in Plasma Physics in Brazil.

Focusing the view on the activities on Plasma Physics at UFRGS, Prof. Dillenburg was the leading influence in the creation of the Plasma Physics group, which started activities in 1974. Immediately after the start of the activities of the group, some visitors were invited to spend some time at the Institute and bring up-to-date information to the people which were starting to study the subject, which was new at the institution. Prof. Dillenburg had a very important role in the choice of the first visitors, and in the choice of the first activities. Some of the interactions started at these initial moments turned out to be very productive and long lasting, as the interaction with the group under the leadership of Dr. Ignazio Fidone, of Fontenay-aux-Roses, France, and the interaction with the group working with Dr. Ching-Sheng Wu of the University of Maryland, USA.

The activities soon gained momentum, and the first batch of Masters and Doctors formed inside the group started to graduate in 1979, and I count myself among them. Again Prof. Dillenburg played a special role. For instance, he appears as advisor or co-advisor of four of the first five Masters in the area of Plasma Physics, between 1979 and 1985. Regarding Ph.D. students, Prof. Dillenburg was the 
advisor to my own thesis, and the co-advisor to the thesis of Dr. Felipe Rizzato, who is also attending to this conference. In both cases, guiding lines were drawn which are connected to the research conducted by the group until the present days, on subjects dealing with electron cyclotron radiation and with nonlinear dynamics.

Regarding Plasma Physics activities at a larger community, it is clear to us that Prof. Dillenburg stands as a prominent figure in the introduction of activities in Plasma Physics in Brazil, not only due to the creation of the Plasma Physics group at UFRGS, but also due to the role played at national level, in the formulation of guidelines for the activities in Plasma Physics. Of particular significance to this meeting is the fact that Prof. Dillenburg was the Chairman to the First
Brazilian Meeting in Plasma Physics, which was held in the city of Santos, in 1991.

We now stop these introductory words. Let Prof. Dillenburg himself take this microphone, and share with us some of his opinions and points of view.

Porto Alegre, December 04, 2003

Luiz Fernando Ziebell 